\title{
Demographics, clinical characteristics, health resource utilization and cost of chronic thromboembolic pulmonary hypertension patients: retrospective results from six European countries
}

Bernd Schweikert ${ }^{*}$, David Pittrow², Carmine Dario Vizza ${ }^{3}$, Joanna Pepke-Zaba ${ }^{4}$, Marius M Hoeper ${ }^{5}$, Anja Gabriel ${ }^{6}$, Jenny Berg ${ }^{7}$ and Mirko Sikirica ${ }^{8}$

\begin{abstract}
Background: Chronic Thromboembolic Pulmonary Hypertension (CTEPH) results from incomplete resolution of a pulmonary embolus, leading to pulmonary hypertension and progressive right heart failure and death. We aimed to describe the demographics, treatment patterns, health resource utilization and related costs of patients with CTEPH.

Methods: In specialized PH centres across six European countries, medical charts of CTEPH patients on PH medication were retrospectively extracted (chart review between 2006 and 2009). Resource utilization was valued using country-specific unit costs. Descriptive statistical analyses were performed.
\end{abstract}

Results: Twenty-one hospitals documented 119 consecutive CTEPH patients over an average of 25.4 months. Patients were inoperable (83.9\%) or persistent after surgery (16.0\%) with mean age $67.5 \pm 12.3$ years, $61 \%$ were female. The average 6-minute walking distance was $298 \pm 120$ meters, and NYHA class II/III/IV was 27/59/14\%. At baseline, 59.7\% patients received endothelin receptor antagonist, 34.4\% phosphodiesterase- 5 inhibitors, and $5.8 \%$ prostacyclin. Adding a second PH medication was the most common regimen change. CTEPH patients experienced $1.8 \pm 2.2$ hospitalizations per year accounting for $14.8 \pm 26.1$ days in hospital. Patients paid on average 2.8 office visits per year to their general practitioner and 1.3 visits to a specialist. Unadjusted annual mortality rate was $6.0 \%$. Annual cost of $\mathrm{PH}$ specific medication was the predominant economic factor averaging $€$ 36,768 per year. Costs for hospitalizations $(€ 4,496)$ and concomitant medications $(€ 2,510)$ were substantially lower. Other health care resource items only accounted for marginal additional costs.

Conclusion: $C T E P H$ patients are characterised by substantial morbidity and mortality. Health care utilisation, predominantly due to off-label use of PH drugs, is significant.

Keywords: Retrospective, Chart review, Pulmonary hypertension, Treatment, Cost

\footnotetext{
* Correspondence: bernd.schweikert@optum.com

'Optumlnsight, Konrad-Zuse-Platz 11, D- 81829 Munich, Germany

Full list of author information is available at the end of the article
} 


\section{Background}

Pulmonary hypertension $(\mathrm{PH})$ is a debilitating disease of the pulmonary artery branches characterized by increased pulmonary arterial pressure and pulmonary vascular resistance [1,2]. The condition is often associated with progressive right ventricular failure and a poor prognosis. An important and cause of $\mathrm{PH}$ is chronic thromboembolic $\mathrm{PH}(\mathrm{CTEPH})$, which is the result of pulmonary vascular obstruction characterized by recurrent, unresolved pulmonary emboli and/or progressive pulmonary vascular thrombosis and scarring [3].

Prospective studies indicate that between $0.6 \%$ and $4.6 \%$ of acute pulmonary embolic survivors develop symptomatic CTEPH $[4,5]$. Furthermore, approximately $30 \%$ to $50 \%$ of CTEPH patients have been reported not having a history of acute venous thromboembolism [6,7].

Due to the rarity and complexity of the condition, patients with CTEPH according to international and national $\mathrm{PH}$ guidelines should be treated in expert centres only [1]. The treatment of choice for CTEPH is surgical pulmonary endarterectomy (PEA), which provides a potential cure of the disease, in particular if performed at expert centres with this surgical capability [8]. However, a substantial portion of patients may be considered 'inoperable' due to distal location of pulmonary thromboembolic or severe comorbidity and have a poor prognosis if untreated $[9,10]$. In addition, roughly $10 \%$ of patients who undergo PEA maintain a pulmonary hypertensive state since they obtain limited relief from surgery or experience recurrence [9]. Such inoperable or residual/recurrent patients are frequently treated with $\mathrm{PH}$ drugs (off-label) due to the lack of other treatment alternatives [11]. To date, positive randomized control trial evidence for medication use in CTEPH has only recently been demonstrated in the CHEST-1 study with riociguat [12]. Only very recently a drug has been approved for the treatment of CTEPH in Europe and the US. Additionally, there is a lack of data on costs and resource utilization associated with CTEPH in patients in the real-world setting.

Against this background, we aimed to describe the demographics, drug treatment patterns, outcomes and costs of patients with CTEPH treated under everyday practice conditions in six European countries.

\section{Methods}

\section{Design and organisation}

This present study was a retrospective chart review in 21 specialist centres in six countries: France (3 centres), Spain (4), Italy (4), UK (3), Sweden (1), and Germany (3). Data from consecutive patients were collected at each site for a maximum of up to 39 months after the initiation visit within the observation period between July 2006 and September 2009. The ethics review boards of each centre approved data collection, and data protection rules were closely observed (see Additional file 1 for a complete list of the involved ethic commissions and review boards). Patients were eligible for inclusion, if they were at least 18 years old, had a confirmed diagnosis of CTEPH (Group 4 according to Dana Point 2008 criteria), were in NYHA class II to IV, treated with monotherapy or combination therapy with endothelin receptor antagonists (ERA), prostacyclin analogues (PA) or phosphodiesterase-5 (PDE-5) inhibitors. The only exclusion criterion was HIV.

Written informed consent was obtained from the patients according to local regulations and in line with the recommendation of the responsible ethic committees and review boards.

\section{Patient variables}

Information was collected on demographics (age, gender, employment status etc.), diagnostic information (type of CTEPH with differentiation between inoperable or operated patients with persisting and recurrent $\mathrm{PH}$ after PEA; time since first diagnosis), clinical data (New York Heart Association [NYHA] class, 6-minute walk distance, Borg dyspnoea index), hemodynamic and lung function (pulmonary artery pressure, pulmonary capillary wedge pressure, pulmonary vascular resistance, right atrial pressure, cardiac index, respiratory capacity), comorbidities and risk factors (smoking, alcohol consumption etc.). Detailed information was collected on treatments focussing on PH drugs, i.e. the endothelin receptor antagonists (ERA) ambrisentan, bosentan, and sitaxentan, the PDE- 5 inhibitors sildenafil and tadalafil, or prostacyclines. Dosages were recorded. Further, co-medication with calcium channel blockers, diuretics and digoxin were recorded at the class level. With respect to outcomes, the following events were recorded: lung or heart lung transplantation, atrial septostomy, PEA, hospitalisation, ambulatory/outpatient centre visits, examinations and procedures, and other health care services.

\section{Data collection}

Data were extracted from patient files by staff members of the individual sites according to guidelines provided for this procedure. Standardized case report forms were used. Data were entered into the database at a central site, and checked for plausibility and completeness. In case of missing data or queries, sites were contacted to resolve the issues. No on-site monitoring was performed.

\section{Statistical analysis}

Due to the nature of the study and the small patient population, all statistical analyses were exploratory and used in a descriptive manner. Incidence rates, time to first event and standard deviations were provided for discrete variables. Means per year of follow-up and standard deviations were presented for continuous variables. For survival analysis, 
Table 1 Baseline characteristics

\begin{tabular}{lcc}
\hline Baseline variable & Sample size $(\mathbf{N}) *$ & Value \\
\hline Age, years (mean \pm SD) & 119 & $67.5 \pm 12.3$ \\
Gender, female, \% & 119 & 60.5 \\
BMI, kg/m² (mean \pm SD) & 112 & $26.8 \pm 5.4$ \\
Comorbidities, number & 119 & $3.4 \pm 1.9$ \\
NYHA class, (mean \pm SD) & 119 & $2.9 \pm 0.6$ \\
Class, II, III, IV (\%) & 119 & $27 / 59 / 14$ \\
6-min walk distance, (mean \pm SD) & 92 & $298 \pm 120$ \\
History of PH, months (mean \pm SD) & 116 & $16.0 \pm 47.3$ \\
Inoperable CTEPH, \% & 118 & 83.9 \\
\hline
\end{tabular}

*Sample size may vary due to missing values in the patient records.

Kaplan-Meier estimates were used. Resource utilization was valued using country-specific unit costs.

\section{Results}

\section{Disposition and characteristics}

Of 119 CTEPH patients, 49 (41.2\%) were documented in France, 34 (28.6\%) in Germany, 17 (14.3\%) in the UK, 9 (7.6\%) in Italy, 7 (5.9\%) in Spain, and 3 (2.5\%) in Sweden. Mean observation time was $25.4 \pm 25.6$ months, and the mean number of recorded visits $7.1 \pm 3.3$. Baseline characteristics are summarized in Table 1 . Patients were on average $67.5 \pm 12.3$ years old, women accounted for $60.5 \%$. Time since PH diagnosis was $16.0 \pm 47.3$ months.

Comorbidities were prevalent (mean number per patient $3.4 \pm 1.9$ ), with the most frequent ones including arterial hypertension (41 patients, $34.2 \%$ ), pulmonary embolism with or without acute cor pulmonale (30.0\%), other pulmonary heart disease (17.5\%), phlebitis and thrombophlebitis (14.2\%), and heart failure or chronic obstructive pulmonary disease (10\% each). Patients were defined as inoperable in 99 cases (83.9\%) and as having persisting or recurrent $\mathrm{PH}$ after PEA in 19 cases $(16.0 \%$; 1 patient with missing information).
Mean 6-minute walking distance was low $(298 \pm 120$ meters). Most patients were in NYHA classes II (26.8\%) or III (58.8\%), and fewer in IV (14.3\%). Hemodynamic are displayed in Table 2. Mean pulmonary arterial pressure was $46 \pm 11 \mathrm{mmHg}$, mean pulmonary vascular resistance $797 \pm 416$ dyn $\times \mathrm{sec} \times \mathrm{cm}^{-5}$.

\section{Medication}

PH drugs were used off-label in CTEPH (Figure 1). At the time of the data collection, monotherapy prevailed, mostly with bosentan (68 patients, 57.6\%), sildenafil (39 patients, $33.1 \%$ ), or epoprostenol (3.4\%). All other drugs were reported in less than $2 \%$ of patients. Combination therapy was reported in 1 patient only (ERA plus PDE-5 inhibitor). As concomitant medications, mainly anticoagulants (62.5\%) and diuretics were noted (59.2\%). Oxygen was used in every fourth patient (25.8\%, Figure 2).

Medication changes over time are shown in Figure 3. Discontinuation of the first therapy was infrequent (6 cases on bosentan and 6 cases on sildenafil, 5.0\% each). Switch from bosentan to another ERA occurred in 16 cases $(13.3 \%)$ and to a PDE-5 inhibitor in 5 cases (4.2\%), while switch from sildenafil to ERA occurred only in 1 patient $(0.8 \%)$, and to other PDE- 5 inhibitors in 5 patients (4.2\%). One patient on epoprostenol $(0.8 \%)$ switched to another prostacyclin, and another patient to an ERA.

Adding a second $\mathrm{PH}$ medication was the most common regimen change. For bosentan, in 29 patients $(24.2 \%)$ a PDE-5 inhibitor was added, in 2 cases (1.7\%) another ERA, and in 1 case $(0.8 \%)$ a prostacyclin. For sildenafil, in 11 cases (9.2\%) an ERA was added and in 1 case $(0.8 \%)$ a prostacyclin. For prostacyclin, in 1 case each $(0.8 \%$ each) an ERA or a PDE-5 inhibitor was added.

\section{Clinical course}

Most patients were relatively stable during follow-up in terms of hemodynamics (Table 2) and events. Six-minute walking distance increased by 30.3 meters. At the last

Table 2 Clinical outcomes and hemodynamics, baseline and change during follow-up

\begin{tabular}{|c|c|c|c|c|}
\hline \multirow[t]{2}{*}{ Parameter } & \multicolumn{2}{|c|}{ Baseline } & \multicolumn{2}{|r|}{ Follow-up } \\
\hline & $\mathbf{N}^{*}$ & Mean \pm SD & $\mathbf{N}^{*}$ & $\Delta$ during observation (Mean \pm SD) \\
\hline 6 MWD, meters & 92 & $298 \pm 120$ & 90 & $30 \pm 90$ \\
\hline Pulmonary atrial pressure (PAP), $\mathrm{mmHg}$ & 107 & $45.5 \pm 0.6$ & 51 & $-2.5 \pm 13.4$ \\
\hline Pulmonary capillary wedge pressure, $\mathrm{mm} \mathrm{Hg}$ & 98 & $9.5 \pm 4.6$ & 43 & $-1.0 \pm 5.9$ \\
\hline Right atrial pressure (RAP), mmHg & 96 & $8.1 \pm 5.8$ & 53 & $-0.43 \pm 6.7$ \\
\hline Pulmonary vascular resistance (PVR), dyn $\times \sec \times \mathrm{cm}^{-5}$ & 94 & $797 \pm 416$ & 37 & $-111 \pm 360$ \\
\hline Cardiac index, I/min $/ \mathrm{m}^{2}$ & 98 & $2.2 \pm 0.5$ & 49 & $1.11 \pm 3.3$ \\
\hline Borg dyspnoea index & 81 & $4.7 \pm 2.2$ & 78 & $-0.5 \pm 2.7$ \\
\hline $\mathrm{FEV}_{1}$, litres & 86 & $2.0 \pm 0.7$ & 71 & $-0.1 \pm 0.3$ \\
\hline $\mathrm{FEV}_{1} /$ vital capacity & 87 & $71.5 \pm 12.3$ & 72 & $-3.1 \pm 10.4$ \\
\hline
\end{tabular}

*Sample size may vary due to missing values in the patient records.

FEV $_{1}$, Forced Expiratory Volume in 1 second; 6-MWD, walking distance in 6 minutes. 


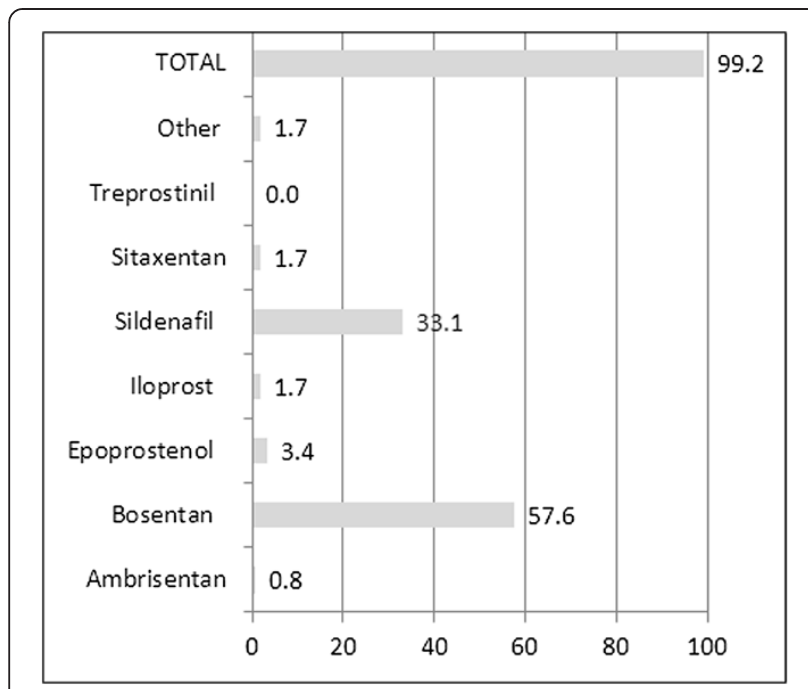

Figure $1 \mathrm{PH}$-specific medication at inclusion (\% of patients).

Medication for $\mathrm{PH}$ at time of inclusion (\% of patients).

observation compared to baseline, 38 patients (31.9\%) had improved with respect to NYHA class, 69\% (58.0\%) had remained stable, and $10(8.4 \%)$ had deteriorated.

Surgical interventions comprised 9 PEA (8.3\%) and 1 atrial septostomy $(0.8 \%)$. A total of 15 patients (12.6\%) died during observation, with an unadjusted annual mortality rate of $6.0 \%$. Time to death in inoperable CTEPH versus residual PH is shown in Figure 4, indicating a substantially higher mortality and significant unmet need for CTEPH patients who are not eligible for PEA surgery.

\section{Resource utilization and costs}

Patients had on average $2.8 \pm 4.2$ office visits with their general practitioner and $1.3 \pm 1.4$ visits to a specialist per year (Table 3$)$. Hospitalisations were frequent (1.8 \pm 2.2 per patient and year), as were examinations or diagnostic tests $(8.4 \pm 5.9)$.
Annual costs of $\mathrm{PH}$ medication was the predominant cost factor $(36,768 € \pm 22,630)$, followed by costs for hospitalisations $(4,496 € \pm 7,923)$ and concomitant medications $(2,510 € \pm 2,503$, Figure 5$)$. Costs for ambulatory visits to GPs and specialists were negligible $(<100 €$ each per patient and year).

Other health care resource items only accounted for marginal additional costs in both groups. Medical aids such as walking aids, inhalation devices or physiotherapy, were documented for one out of four patients.

\section{Discussion}

The present analysis provides insight about the situation and resource utilisation of CTEPH patients in a sample of European specialist centres during the years 2006 to 2009. In line with a report of a large-scale European registry performed in 2007 to 2009 [6], our study shows that off-label treatment with $\mathrm{PH}$ drugs is common practice in patients with inoperable or residual CTEPH. Most patients were severely impaired as indicated by their NYHA class, exercise capacity (6-minute walk distance), hemodynamics and comorbidities. Compared to patients in the international prospective CTEPH registry performed in 2007-2009, patients in our cohort were somewhat older (68 versus 63 years), comprised more women (61\% versus 50\%), had a lower 6-minute walking distance (298 versus 329 meters), and a lower portion of inoperable patients (83\% versus $36 \%$ ) [6].

Drug treatment accounted for the largest share of direct costs for patients in the present chart review, while costs for hospitalisations and concomitant treatment were much lower, and costs for GP or specialists visits were negligible. To our knowledge, there are only two other studies that also reported the cost dimension of patients with CTEPH. First, Kirson et al. reported a series of 289 privately insured CTEPH patients in the US (mean age 52.2 years, 57.1\% women), for whom mean direct costs per month (year

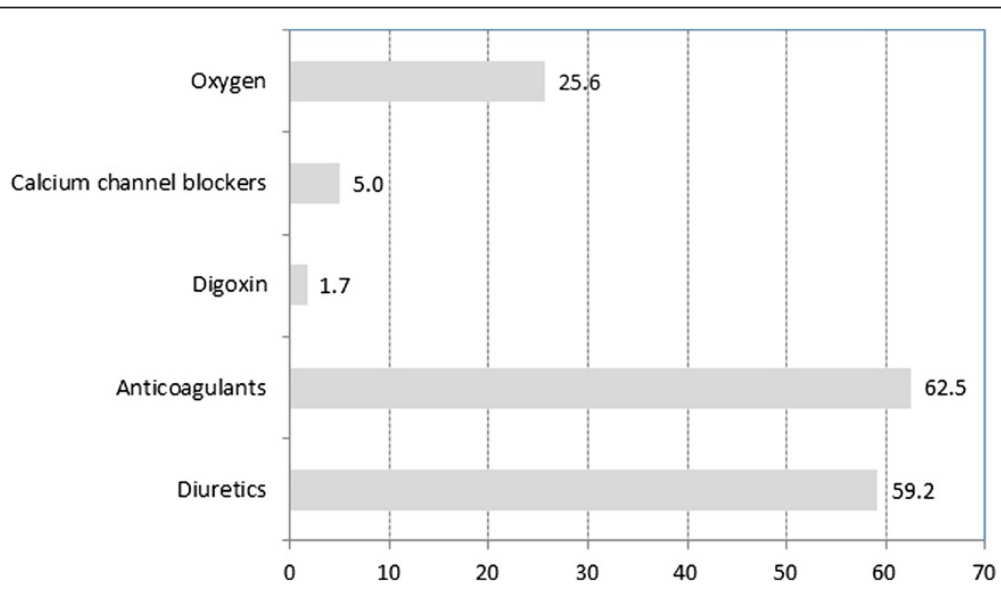

Figure 2 Co-medication and accompanying treatment (\% of patients). Co-medication and accompanying treatment at time of inclusion. 


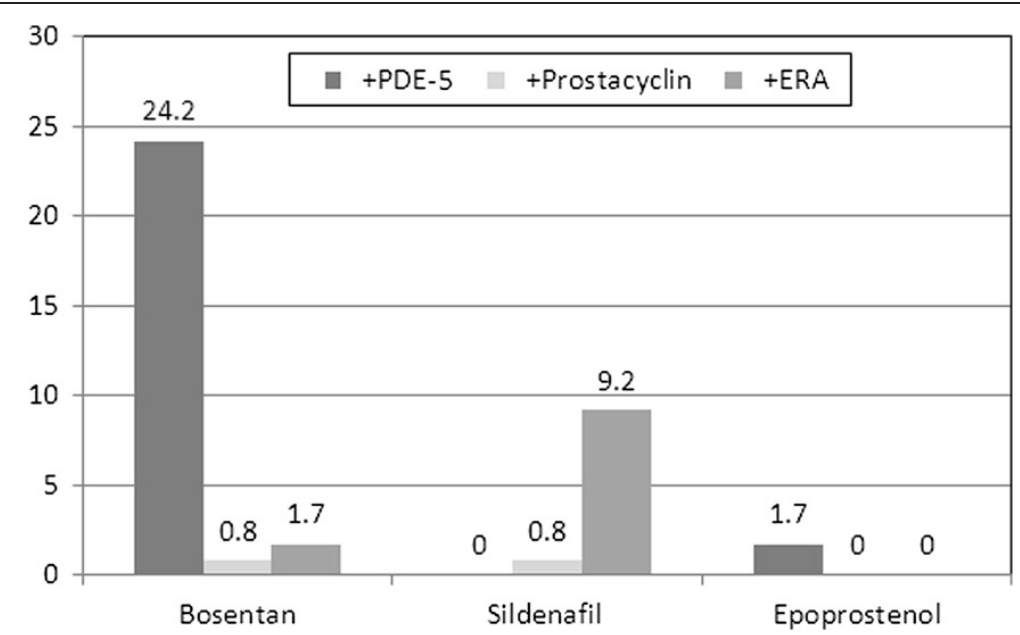

Figure 3 Changes in treatment during follow-up (percent of patients). Percentage of patients on medication for the three most common medications.

2007 values) were USD 4782 [USD 57,384 annualized] compared to USD 511 [6132/year] for controls, $(\mathrm{p}<$ 0.0001 ), and USD 2,023 [USD 24,276/year] for patients with pulmonary arterial hypertension (PAH) $[13,14]$. In that sample, inpatient services accounted for 54\%, outpatient and other services for 33\% and prescription drugs for $11 \%$ of total direct healthcare costs per patient-month in CTEPH patients [13]. Second, Said et al. estimated direct medical costs and resource use for commercially insured CTEPH patients during 2004-2009 within the US-American MarketScan database using a retrospective cohort design [15]. Compared to matched controls without CTEPH or PAH, CTEPH patients had significantly higher monthly costs and resource use (total costs 6198 USD [\$74,376/year] versus 1,579 USD [\$18,948/year], outpatient visits 1.2 versus 0.8 , inpatient visits 2 versus 0.2 , prescriptions 4.2 versus 2.8 ; all p-values $<0.05$ ) [15].

Other groups have published cost-utility [16], costeffectiveness [17] or cost-minimisation analyses [18] for PAH (but not CTEPH) based on populations in the USA or Canada. For example, in a retrospective study similar to ours (claims database analysis) with $706 \mathrm{PAH}$ patients in a large, geographically diverse US managedcare organization, PAH drugs were the main cost driver compared to PAH-related inpatient stays and emergency department visits, with average monthly costs of 5,332

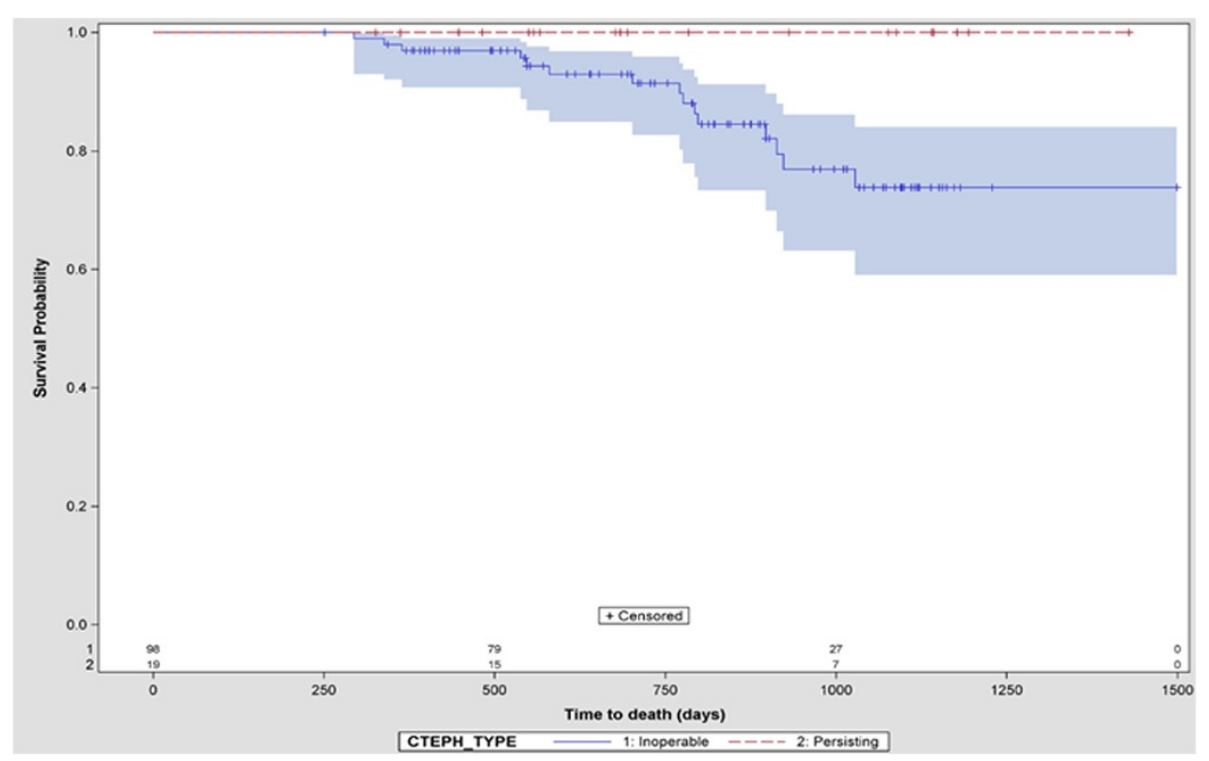

Figure 4 Survival, by PEA status. Kaplan-Meier curve of survival by status of pulmonary endartherectomy: blue = inoperable, red = persisting CTEPH after PEA. 
Table 3 Resource utilization

\begin{tabular}{lccc}
\hline Resource & $\mathbf{N}^{*}$ & Mean \pm SD & Median \\
\hline Hospitalizations per PY & 118 & $1.8 \pm 2.2$ & 1.0 \\
Hospitalization days per PY & 74 & $14.8 \pm 26.1$ & 7.8 \\
Time to first hospitalization (d) & 74 & $146 \pm 209$ & 71.5 \\
Examinations/tests per PY & 118 & $8.4 \pm 5.9$ & 7.8 \\
Visits to the GP per PY & 64 & $2.8 \pm 4.2$ & 0.7 \\
Visits to specialists per PY & 77 & $1.3 \pm 1.4$ & 0.9 \\
Medical aids per PY & 48 & $0.6 \pm 2.1$ & 0 \\
\hline
\end{tabular}

*Sample size may vary due to missing values in the patient records.

$\mathrm{D}=$ day; $\mathrm{GP}=$ general practitioner; $\mathrm{PY}=$ patient year

USD for bosentan and 3,632 USD for sildenafil patients, respectively $(\mathrm{p}=0.003)[19]$.

\section{Limitations of the study}

A number of methodological considerations and limitations have to be taken into account when interpreting the current data. Data have to be interpreted carefully taking the principle limitations of a retrospective analysis into account, in particular: missing data, varying follow-up periods for patients, variation in reporting and documentation across sites and countries [20]. The comprehensive measurement of health care utilization is known to be challenging in studies which cannot rely on administrative data (preferably payer data).

It was anticipated that the availability of these types of utilization data depended on the country or even sitespecific degree of service integration as well as the informational exchange across health care service providers (e.g. $\mathrm{PH}$ treatment centre and general practitioner). Missing data in particular with respect to medical aids were frequent. Therefore a total cost estimate could not be provided, as it would have been based on the small

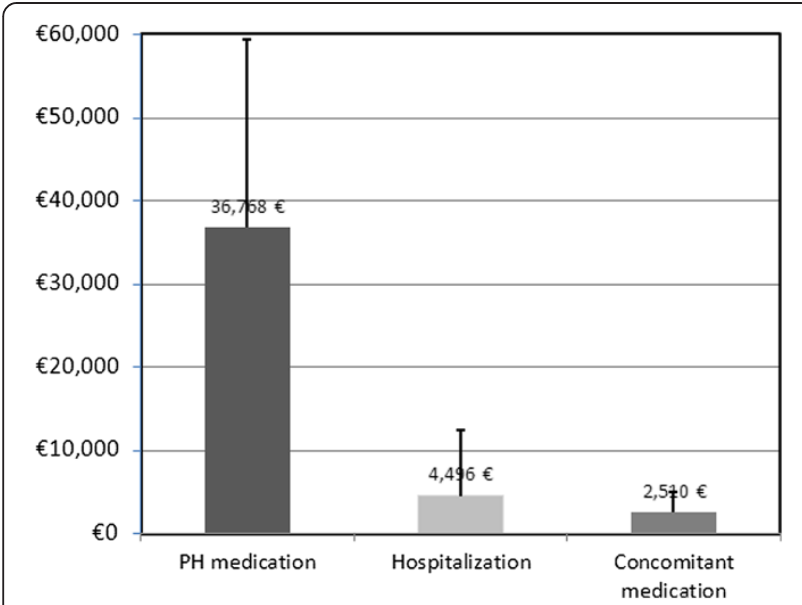

Figure 5 Yearly costs related treatment of CTEPH. Mean annualized cost of health care related to CTEPH treatment. Main treatment categories. Whiskers represent standard deviation. sample of patients when restricting aggregation to the patients with complete information. Relying on available information would have led to significant underestimation of total costs. However, the direct costs for medications outnumber other cost components by far.

Furthermore, the study focused on inoperable CTEPH patients treated with $\mathrm{PH}$ medication excluding patients that were not on PH medication. Although no PH medication had been approved for CTEPH at the time of the study, ERA, PA and PDE-5 inhibitors have already been widely used as suggested by guidelines as the treatment of choice. A further obvious limitation is the sample size of this study and the selection process using a centre-based approach. However, given the severity and rareness of the disease and the still limited number of observational studies investigating the condition, this study adds to the knowledge base by reporting clinical and economic outcomes from a real world sample.

\section{Conclusions}

While CTEPH is the only form of PH that currently can be potentially cured, a substantial portion of patients are either inoperable or decline operation, or experience recurrent PH after the PEA. Physicians face a dilemma when treating such patients, as no drug has consistently demonstrated efficacy and received regulatory approval for the treatment of CTEPH. In the present study, CTEPH patients who were inoperable had a significantly worse prognosis compared to patients post-PEA. CTEPH patients had high resource utilization and costs, with off-label $\mathrm{PH}$ medications accounting for the highest costs. More research is required in the real-world setting to understand the cost implications of using off-label medications without demonstrated efficacy in randomized controlled trials.

\section{Additional file}

Additional file 1: List of involved ethic committees and review boards by country.

\section{Abbreviations}

CTEPH: Chronic thromboembolic pulmonary hypertension; ERA: Endothelin receptor antagonist; EUR: Euro; NYHA: New York Heart Association; PA: Prostacyclin analogues; PEA: Pulmonary endatherectomy; PDE-5: Phosphodiesterase-5; PAH: Pulmonary arterial hypertension; PH: Pulmonary hypertension; UK: United Kingdom; USD: US dollars.

\section{Competing interest}

The study was sponsored by Bayer Pharma AG. BS and JB are employees of Optumlnsight who were paid consultants to Bayer Pharma AG in connection with the development, conduct and disseminations of this study. DP received grants from Bayer Pharma AG for consultation services. DCV has received financial grants from Bayer Pharma AG, Actelion, GSK, Pfizer, Italfarmaco, Dompè, UTEL, and Lilly for lectures and consultation services. $\mathrm{MH}$ has received financial grants from Bayer Pharma AG, Actelion, GSK, Lilly, Novartis and Pfizer for consultation services. JPZ has received reimbursements of travel expenses to congresses and speakers' fees from Actelion, Pfizer, GSK, Bayer Pharma AG, Lilly and United Therapeutics, has 
participated to advisory boards for Actelion, Bayer Pharma AG, GSK, Pfizer Lily, and has received funds for research/education from Actelion, Pfizer Bayer Pharma AG, GSK. AG and MS are employees of Bayer Pharma AG.

\section{Authors' contributions}

BS participated in the design of the study, co-managed data collection and study conduct and carried out the statistical analysis. DP participated in design and analysis of the study and drafted the manuscript. DCV, JPZ and $\mathrm{MH}$ provided medical expertise, participated in the coordination of data collection and study conduct and interpretation of results. AG conceived the study and participated in its design coordination. JB participated in the design and coordination of the study and the statistical analysis. MS participated in study coordination, and analysis. All authors read and approved the final manuscript.

\section{Acknowledgements}

This study was funded by Bayer Pharma AG, Berlin, Germany.

Data were collected and analyses were performed by Optumlnsight.

\section{Author details}

'OptumInsight, Konrad-Zuse-Platz 11, D- 81829 Munich, Germany. ${ }^{2}$ Institute for Clinical Pharmacology, Technical University, Dresden, Germany. ${ }^{3}$ Department of Cardiovascular and Respiratory Science, School of Medicine University of Rome "Sapienza", Rome, Italy. ${ }^{4}$ Papworth Hospital NHS Trust, Cambridge, United Kingdom. ${ }^{5}$ Hanover Medical School, Hanover, Germany. ${ }^{6}$ Bayer Pharma AG, Wuppertal, Germany. ${ }^{7}$ Optumlnsight, Stockholm, Sweden. ${ }^{8}$ Bayer Pharma AG, Berlin, Germany.

Received: 20 June 2013 Accepted: 30 May 2014

Published: 9 June 2014

\section{References}

1. Galie N, Hoeper MM, Humbert M, Torbicki A, Vachiery JL, Barbera JA, Beghetti M, Corris P, Gaine S, Gibbs JS, Gomez-Sanchez MA, Jondeau G, Klepetko W, Opitz C, Peacock A, Rubin L, Zellweger M, Simonneau G, Vahanian A, Auricchio A, Bax J, Ceconi C, Dean V, Filippatos G, Funck-Brentano C, Hobbs R, Kearney P, McDonagh T, McGregor K, Popescu BA, et al: Guidelines for the diagnosis and treatment of pulmonary hypertension: The Task Force for the Diagnosis and Treatment of Pulmonary Hypertension of the European Society of Cardiology (ESC) and the European Respiratory Society (ERS), endorsed by the International Society of Heart and Lung Transplantation (ISHLT). Eur Heart J 2009, 30:2493-2537.

2. Barst RJ, Gibbs JS, Ghofrani HA, Hoeper MM, McLaughlin W, Rubin $\sqcup$, Sitbon O, Tapson VF, Galie N: Updated evidence-based treatment algorithm in pulmonary arterial hypertension. J Am Coll Cardiol 2009, 54:S78-S84.

3. Mehta S, Helmersen D, Provencher S, Hirani N, Rubens FD, De Perrot M, Blostein M, Boutet K, Chandy G, Dennie C, Granton J, Hernandez P, Hirsch AM, Laframboise K, Levy RD, Lien D, Martel S, Shoemaker G, Swiston J, Weinkauf J: Diagnostic evaluation and management of chronic thromboembolic pulmonary hypertension: a clinical practice guideline. Can Respir J 2010, 17:301-334.

4. Korkmaz AN, Colak MO, Vural C: Pulmonary plasmacytoma, incidentally detected by myocardial perfusion scintigraphy. J Nucl Cardiol 2012, 19:1083-1084

5. Klok FA, van Kralingen KW, van Dijk AP, Heyning FH, Vliegen HW, Huisman MV: Prospective cardiopulmonary screening program to detect chronic thromboembolic pulmonary hypertension in patients after acute pulmonary embolism. Haematologica 2010, 95:970-975.

6. Pepke-Zaba J, Delcroix M, Lang I, Mayer E, Jansa P, Ambroz D, Treacy C, D'Armini AM, Morsolini M, Snijder R, Bresser P, Torbicki A, Kristensen B, Lewczuk J, Simkova I, Barbera JA, De Perrot M, Hoeper MM, Gaine S, Speich R, Gomez-Sanchez MA, Kovacs G, Hamid AM, Jais X, Simonneau G: Chronic thromboembolic pulmonary hypertension (CTEPH): results from an international prospective registry. Circulation 2011, 124:1973-1981.

7. Peacock A, Simonneau G, Rubin L: Controversies, uncertainties and future research on the treatment of chronic thromboembolic pulmonary hypertension. Proc Am Thorac Soc 2006, 3:608-614.

8. Rahnavardi M, Yan TD, Cao C, Vallely MP, Bannon PG, Wilson MK: Pulmonary thromboendarterectomy for chronic thromboembolic pulmonary hypertension : a systematic review. Ann Thorac Cardiovasc Surg 2011, 17:435-445.
9. Rubin L: Pulmonary thromboembolic disease-diagnosis, management and prevention. Am J Med Sci 1985, 290:167-177.

10. Riedel M, Stanek V, Widimsky J, Prerovsky I: Longterm follow-up of patients with pulmonary thromboembolism. Late prognosis and evolution of hemodynamic and respiratory data. Chest 1982, 81:151-158.

11. Seyfarth HJ, Halank M, Wilkens H, Schafers HJ, Ewert R, Riedel M, Schuster E, Pankau H, Hammerschmidt S, Wirtz H: Standard PAH therapy improves long term survival in CTEPH patients. Clin Res Cardiol 2010, 99:553-556.

12. Ghofrani HA, D'Armini AM, Grimminger F, Hoeper MM, Jansa P, Kim NH, Mayer E, Simonneau G, Wilkins MR, Fritsch A, Neuser D, Weimann G, Wang C: Riociguat for the treatment of chronic thromboembolic pulmonary hypertension. N Engl J Med 2013, 369:319-329.

13. Kirson NY, Birnbaum HG, Ivanova Jl, Waldman T, Joish V, Williamson T: Excess costs associated with patients with chronic thromboembolic pulmonary hypertension in a US privately insured population Appl Health Econ Health Policy 2011, 9:377-387.

14. Kirson NY, Birnbaum HG, Ivanova Jl, Waldman T, Joish V, Williamson T: Excess costs associated with patients with pulmonary arterial hypertension in a US privately insured population. Appl Health Econ Health Policy 2011, 9:293-303.

15. Said Q, Martin BC, Joish VN, Kreilick C, Mathai SC: The cost to managed care of managing pulmonary hypertension. J Med Econ 2012, 15:500-508.

16. Garin MC, Clark L, Chumney EC, Simpson KN, Highland KB: Cost-utility of treatments for pulmonary arterial hypertension: a Markov statetransition decision analysis model. Clin Drug Investig 2009, 29:635-646.

17. Chen YF, Jowett S, Barton P, Malottki K, Hyde C, Gibbs JS, Pepke-Zaba J, Fry-Smith A, Roberts J, Moore D: Clinical and cost-effectiveness of epoprostenol, iloprost, bosentan, sitaxentan and sildenafil for pulmonary arterial hypertension within their licensed indications: a systematic review and economic evaluation. Health Technol Assess 2009, 13:1-320

18. Dranitsaris $\mathrm{G}$, Mehta $\mathrm{S}$ : Oral therapies for the treatment of pulmonary arterial hypertension: a population-based cost-minimization analysis. Appl Health Econ Health Policy 2009, 7:43-59.

19. Angalakuditi M, Edgell E, Beardsworth A, Buysman E, Bancroft T: Treatment patterns and resource utilization and costs among patients with pulmonary arterial hypertension in the United States. J Med Econ 2010, 13:393-402.

20. Motheral B, Brooks J, Clark MA, Crown WH, Davey P, Hutchins D, Martin BC, Stang P: A checklist for retrospective database studies-report of the ISPOR Task Force on Retrospective Databases. Value Health 2003, 6:90-97.

\section{doi:10.1186/1472-6963-14-246}

Cite this article as: Schweikert et al:: Demographics, clinical characteristics, health resource utilization and cost of chronic thromboembolic pulmonary hypertension patients: retrospective results from six European countries. BMC Health Services Research 2014 14:246.

\section{Submit your next manuscript to BioMed Central and take full advantage of:}

- Convenient online submission

- Thorough peer review

- No space constraints or color figure charges

- Immediate publication on acceptance

- Inclusion in PubMed, CAS, Scopus and Google Scholar

- Research which is freely available for redistribution 